\section{BRITISH GELATINE AND GLUE RESEARCH ASSOCIATION \\ ANNUAL GENERAL MEETING AND THIRD RESEARCH PANEL MEETING}

$\Gamma$

HE second annual general meeting of the British Gelatine and Glue Research Association was held at the Waldorf Hotel, London, W.C.1, on February 7. The director of research, A. G. Ward, in presenting the Council's report*, gave an account of the organization which had been established. During the past year the laboratory premises have been acquired at 2/4 Dalmeny Avenue, Holloway, London, N.7 ; these premises were previously occupied by the British Food Manufacturing Industries' Research Association, and they have been adapted and equipped to the needs of the British Gelatine and Glue Research Association. There are now separate laboratories for general chemistry, bacteriology, chromatography, physical chemistry, physics, constant-temperature work, and technical work, together with three rooms for balances, autoclaving and stores, respectively; in addition, there are the usual technicians' workshops, reading room and library, and clerical offices. The staff consists at present of one senior research officer and three officers, who with the director of research will carry out the programme of fundamental research, and one senior research officer has been appointed to look after the more technical work. A bacteriologist, who will also undertake independent work, an instrument mechanic, research assistants and secretarial staff bring the total number to fourteen.

The immediate objective of the research programme is the study of the structure and physical properties of gelatine. Being the product of the degradation of collagen, gelatine is not a homogeneous substance, and it is necessary in determining its structure to measure the distribution of molecular weights and sizes, as well as the chemical composition; the nature of the degradation process is also a problem of importance. This, then, is the fundamental research that is being undertaken in conjunction with the short-term work, which is mainly of a practical and empirical nature. In addition, the Association has been issuing two quarterly publications : the first, the "Bulletin", reports on activities of the Association and the industry, and is a medium for publishing small items of research; the other, "Abstracts", reviews all relevant literature relating to the gelatine and glue industry.

The third research panel meeting of the Association was held at Beale's Restaurant, Holloway Road, London, N.7, on February 8. In addition to representatives of member firms, there were numerous visitors, including Prof. F. J. W. Roughton and B. G. McLellan, and representatives of government laboratories and of other research associations. Members of three of the research panels of the British Food Manufacturing Industries' Research Association were also present. The chair was taken by the chairman of the British Gelatine and Glue Research Association, S. G. Hudson.

The first two meetings of the panel having been devoted to the consideration of the raw materials of gelatine and glue manufacture and the properties and methods of study of these substances, the papers at

* British Gelatine and Glue Research Association. Second Annual Report for the Year October 1949 to September 1950 (from the Kegistered Office at Sardinia House, 52 Lincoln's Inn Fields, London,
W.0.2). this third meeting dealt with various aspects of the uses of gelatine and glue. The session was opened by E. H. Moore, of Messrs. A. Adams and Co., Ltd., with a contribution entitled "The Use of Gelatine and Animal Glue in Industry". Mr. Moore emphasized the importance of research into the uses of gelatine and glue, to be undertaken along with fundamental research so as to provide a balanced programme of work. In addition, more is required to be done to see that the existing body of information on the uses of gelatine and glue is widely known and used. Animal glues still have very widespread uses in, for example, the wood-working trades; but vigorous action is needed to see that they are not displaced by other materials, either through lack of publicity by the industry or by unnecessarily stringent specifications.

The second paper, on "Some Special Problems Connected with the Use of Gelatine in Foodstuffs", was given by J. W. Selby, of the British Food Manufacturing Industries' Research Association. The food manufacturing industries use some 7,500 tons of gelatine annually, and its simpler analytical characteristics are now defined by law. The statutory instrument specifies upper limits for ash content, arsenic, heavy metals, etc., based on the assumption that gelatine seldom constitutes more than ten per cent of an article of food. There is, however, the possibility that more stringent limits might be applied, and might be extended to include standards of bacteriological purity. Turning to the physical properties of gelatine, Mr. Selby stressed the great importance of high jelly strength. It is also desirable that jelly strength should change as little as possible with the temperature of measurement. Similarly, in many applications the melting and setting characteristics are important, but viscosity of solutions plays only a minor part. Tendency to foam is a disadvantage in most applications.

Mr. G. F. Glover, of the Wiggins Teape Group Research Organization, gave the last paper of the morming session, "Paper Sizing". Tub sizing is performed by running the paper through a bath of gelatine or glue solution before drying. Its function is either to provide an ink-resistant surface and improve the surface resistance to abrasion, or to increase the dry or wet strength of the paper. To secure application mainly in the surface layers, a solution of fairly high viscosity is needed. This is frequently obtained by using a medium-viscosity gelatine or glue with the addition of alum. Temperature control is also important. When penetration through the paper is required in order to modify the bulk properties, higher temperatures, lower viscosities and more prolonged immersion are used. It is common practice to prepare one week's supply of sizing solution at a time. This involves degradation problems, although bacterial attack is effectively prevented by suitable preservatives.

In the afternoon, R. C. M. Smith, of Messrs. Ilford, Ltd., read a paper on "Some Aspects of the Use of Gelatine in the Photographic Industry". Gelatine is unique in possessing a combination of properties which makes it suitable as a medium for the preparation of light-sensitive silver halide dispersions. Its suspending power is one of the most important properties. In this connexion, Mr. Smith mentioned the work of Sheppard and his colleagues on the adsorption of gelatine to silver bromide. The sol-gel transformation plays a great part in making possible some of the manipulations necessary in the prepara. 
tion of modern film, and its mechanism is important to photographic manufacturers. Processing and some stages of the manufacture are only possible because of the ease of diffusion of ions and molecules in the medium into and out of gelatine. For special purposes, it is sometimes necessary either to harden or even insolubilize the gelatine, or to soften it, and gelatine can easily be modified in these ways. Gelatine has a profound effect on the sensitivity of the emulsions, and much work has been carried out on this; but the mechanism of the action is still not completely understood. It is desirable that the gelatine should be of uniform standard from batch to batch, particularly with respect to viscosity and sensitizing power.

\section{CAUSATION AND EXPLANATION IN THEORETICAL BIOLOGY}

IN a recent issue of the British Journal for the I Philosophy of Science (1, No. 4; February 1951), J. S. Wilkie considers some of the classical problems of explanation in biology in the light of a relative theory of causation. A cause is taken to be some factor to which is attributed the disturbance of some regularity. Living things are extremely complex systems in which the parts have causal relations inter se: the regular rhythm of the heart is disturbed by nervous stimulation; the regularity of an undifferentiated field of competent ectoderm is disturbed by the presence of an optic vesicle near some part of the field. But living things as relatively isolated systems can themselves be considered as complex regularities which are disturbed by environmental interference. Reaction with the environment can be considered as constituting a causal event only if there is some assignable disturbance of some regularity of the system : since the system is not totally isolated, it will have regular and constant relations with its environment which are necessary to its maintenance as a system; thus the entry of oxygen into the system cannot as such be considered as a causal relation with the environment. On the other hand, episodic changes such as a temporary increase or diminution of oxygen in the immediate environment definitely disturb the rhythms of the organism and can thus be considered as causal. Among such episodic causal events are the reactions of environmental changes with the sense-organs.

Whatever can be deduced from the known properties of the system alone receives explanation, but not causal explanation.

Mnemic phenomena introduce causal events of peculiar interest. With respect to the organism they are causal, since there is nothing in the structure of the organism from which we can deduce the memories it acquires. Whereas in reflex activity the organism behaves as an elastic system, in memorizing it behaves as an inelastic system. Mnemic traces, considered as imposed upon the structure common to a species, are consequences of causal events and therefore causal themselves with respect to the specific regularity of the species. But mnemic traces do not rernain indifferent to one another, as do the traces left in the wood of a tree by wet and dry seasons; they become organized inter se. Thus the behaviour of these traces has its own regularities which, since they are regularities, might be explained by a knowledge of the properties of the materials of the system (as cleavage patterns can be explained by molecular forces). This, however, appears improb. able, since the physical language lacks the necessary concepts (constructs) under which the peculiar behaviour of mnemic traces could be subsumed. Physical attractions all appear as functions of space and time, whereas mnemic attractions appear as functions of space, time and similarity.

Wilkie also attempts to justify teleological explanations; but it is not considered appropriate to treat these as causal explanations.

\section{FORESTRY COMMISSION ANNUAL REPORT FOR 1949}

7 HE thirtieth annual report of the Forestry Commissioners covering the year ending Sep. tember 30,1949 , has recently been published*. Since the passing of the Forestry Bill in 1919, the Commission has published quinquennial reviews of the work done, in 1924, 1929 and 1934. The Second World War brought the gap to fifteen years, the present report being the first to be issued since the War ended.

In the thirty years of its existence the Forestry Commission has acquired an area of 1,500,000 acres, of which 971,000 were classified at the time of acquisition as plantable. In addition, 57,000 acres of standing woodland have been acquired. By the aid of planting grants, private owners planted 182,000 acres. Planting operations were of necessity severely interrupted during the Second World War.

With regard to the plantations, which range from 1 to 30 years in age, there is a total of 550,624 acres, of which 515,666 are conifers and 34,958 hardwood trees. The youngest ones, $1-5$ years old, cover the largest area $(123,483$ acres $)$, while the oldest, 26-30 years, the smallest $(32,959$ acres). These latter are now producing some revenue. Furthermore, there is what the Commissioners term a by-product, namely, the establishment at a small cost of six national forest parks comprising 240,000 acres.

Other minor Forestry Acts have been passed since 1919 : the Act (Transfer of Woods) of 1923, which empowered the transfer of the majority of the existing Crown woods-for example, the New Forest, Forest of Dean - to the Commission, and in $1927 \mathrm{a}$ short Act authorizing an increase in the number of Commissioners and empowering them to make bylaws with respect to their properties. The issue in 1943 of a report by the Commissioners on post-war forest policy resulted in the Forestry Act of 1945. The Act brought into force ministerial responsibility for future forest policy, an action which was by then very justifiable. The Minister for Agriculture and Fisheries was responsible for England and Wales, while Scotland came under the Secretary of State, the lands acquired since 1919 being invested under the appropriate Minister.

A further measure of the Forestry Act of 1947 provided for the dedication of private woodland to forestry purposes, and dealt with such matters as the enforcement of dedication covenants in England and Wales and of dedication agreements in Scotland. This measure proved very contentious, and has been subject to considerable modifications.

Lastly, a New Forest Act, 1949, was passed just after the period of this report. The Act amends the

* Forestry Commission. Thirtieth Annual Report of the Forestry Commissioners for the Year ending September 30th, 1949. Pp.
15 plates. (London: H.M. Stationery Offlce 1950.) 48. net. 